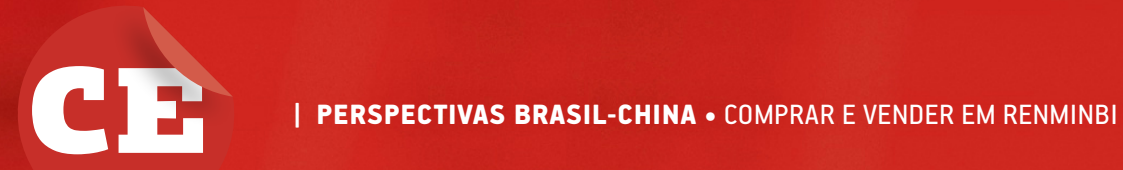

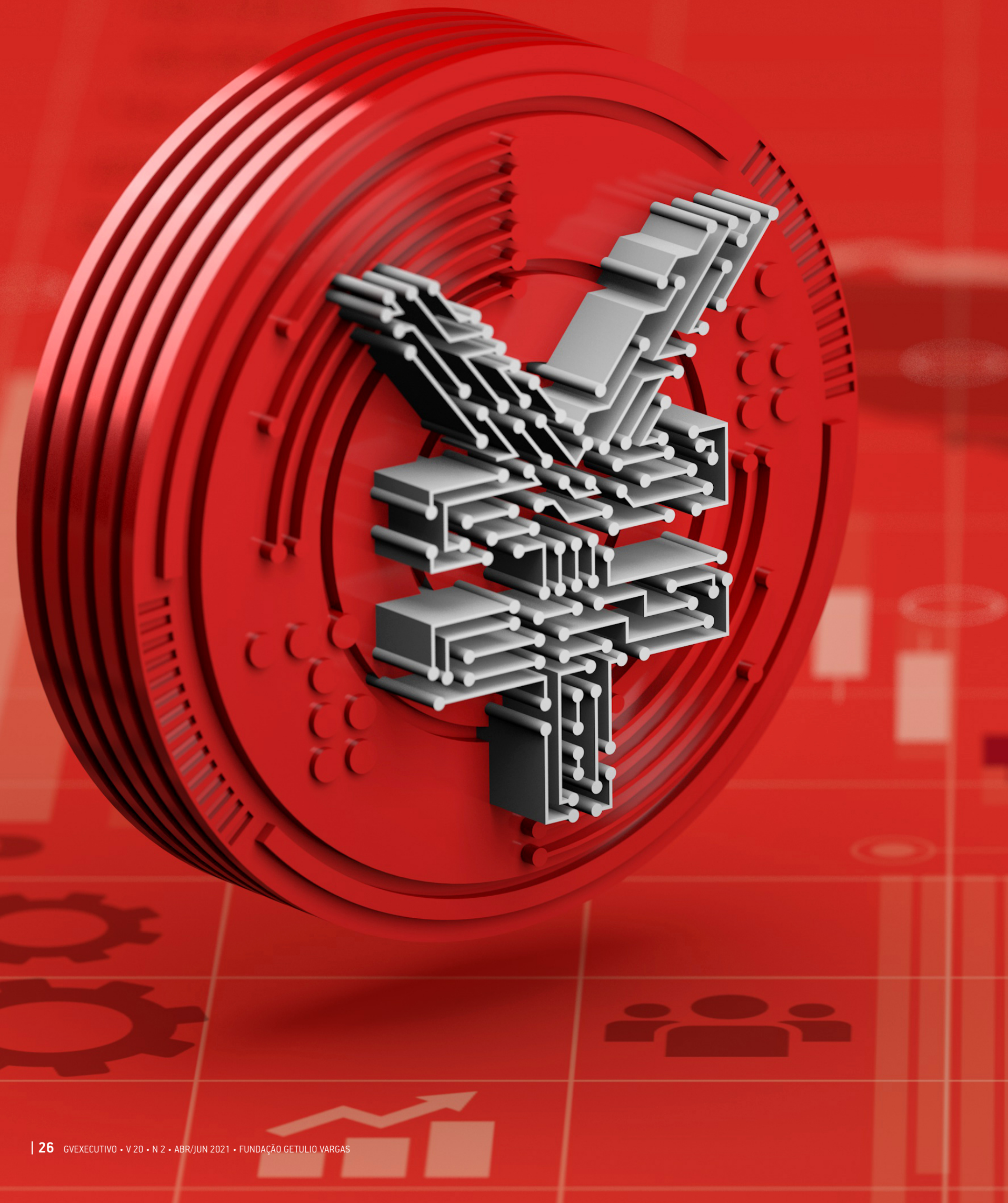




\section{COMPRAR E VENDER EM RENMINBI}

I POR AMANDA LEITNER THOMAZONI E HSIA HUA SHENG

\section{Negociar contratos comerciais diretamente na moeda chinesa evita a intermediação da conversão do dólar e facilita o acesso de empresas brasileiras ao mercado asiático, mas ainda há questões de liquidez, confiabilidade e previsibilidade.}

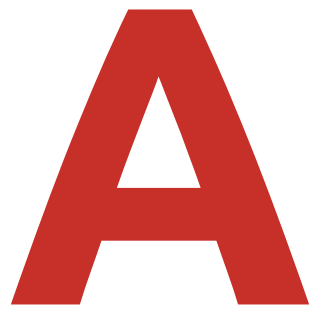

China é atualmente a segunda maior economia do mundo e um dos maiores consumidores de commodities do Brasil. Seu crescimento e expansão global fazem-se presentes pelo programa de internacionalização de sua moeda, renminbi (RMB) ou yuan (CNY), e pela maior presença do país em fóruns internacionais como os da Organização Mundial do Comércio (OMC). Assim, o RMB cresce em participação na economia mundial.

O desenvolvimento das técnicas bancárias na China e o aumento da sua moeda em circulação colocaram o RMB como a moeda que mais cresce nas transações da Ásia, o que tem feito com que ganhe grande relevância em outras regiões. Com crescimento de $6 \%$ de volume transacionado entre 2018 e 2019, a bolsa de Hong Kong tem fortalecido sua posição como centro de RMB offshore.

Além do interesse da própria China pela internacionalização de sua moeda, também há a tendência por parte de seus parceiros comerciais de aceitar mais RMB nos contratos comerciais. Apesar de negociados na China, atualmente a maior parte dos contratos de compra e venda de commodities é realizada em dólar. Esse fato vem trazendo questionamentos. Não seria melhor para as empresas mudar de parâmetro e negociar diretamente na moeda chinesa, sem precisar de intermediação da conversão pelo dólar?

No caso da relação Brasil e China, o crescimento do comércio entre os dois países faz com que o uso do RMB te- nha ganhado mais espaço nos negócios. O exportador chinês vem preferindo fazer acordos comerciais com as empresas brasileiras em RMB em vez de em dólar, pois se sente mais confortável em realizar as transações na moeda à qual os seus custos estão atrelados, e essa preferência por RMB também é verdadeira quando um importador chinês compra commodities no Brasil.

Esse movimento tem estimulado a criação de produtos financeiros para atender à maior demanda por RMB. A abertura do mercado financeiro da China e o maior incentivo à globalização da sua moeda também levam os bancos chineses a criar operações e serviços financeiros competitivos para ajudar as empresas e os parceiros que querem fazer contrato em RMB.

\section{BENEFÍCIOS E RISCOS}

Quais potenciais vantagens e desvantagens do uso do RMB para empresas brasileiras? Nossas pesquisas, com base em entrevistas e artigos publicados nas mídias brasileiras, mostram que o comércio em RMB e a utilização de contratos nessa moeda têm permitido aos exportadores brasileiros ampliar suas transações comerciais no continente asiático como um todo. A China é o maior parceiro comercial no sudeste asiático, e sua moeda é bastante utilizada nas negociações e transações entre as empresas da região.

No entanto, se por um lado há diversos benefícios do uso de RMB por empresas brasileiras, também se destacam alguns pontos de atenção. Embora o mercado de câm- 
bio na China esteja em processo de desregulamentação e de maior abertura para bancos estrangeiros, os investidores e empresários brasileiros ainda se veem à mercê de intervenção política e pouca transparência em termos de informações do mercado.

A falta de uma base de projeção de tendência de câmbio no longo prazo também é apontada por empresários brasileiros como um entrave para o maior uso de RMB para contratos de negócio mais longos. Ainda são recentes a internacionalização de RMB e a formação de reservas internacionais nessa moeda. Segundo relatório do Fundo Monetário Internacional (FMI), as reservas internacionais em RMB têm aumentado aceleradamente ano a ano, porém ainda são inferiores às lastreadas em moedas internacionais mais antigas como o dólar e o euro.

\section{HEDGE}

Com riscos maiores em usar RMB nos contratos de longo prazo, muitos empresários e investidores brasileiros visualizam vantagens em assinar contratos de RMB nos negócios de curto e médio prazos, mas, para isso, precisam resolver uma questão administrativa/contábil: como fazer hedge dos contratos em RMB tendo em vista que a moeda funcional da contabilidade das empresas no Brasil é expressa geralmente em dólar ou na moeda nacional, o real?

Imagine, por exemplo, um exportador brasileiro que vendeu soja para um comerciante na China. Ao concluir a transação, ele enviou o produto e realizou um contrato de venda em RMB. Seu balanço patrimonial, assim como os demais demonstrativos, é em real, pois precisa ser entregue às autoridades brasileiras. A fim de cumprir o requerimento de reportar seu balanço na moeda funcional, o exportador terá de converter a receita dessa transação para real. Ele ficará suscetível a variações na receita por alterações na taxa de câmbio, pois fixou seu preço em RMB na cotação do dia em que fechou negócio, mas só vai receber do comprador em seis meses. Se o real desvalorizar nesse período, sua receita aumentará, porém, caso valorize, a receita diminuirá.

Para reduzir riscos de variação cambial como esse, os empresários brasileiros têm procurado hedges, ou seja, operações financeiras que são proteções oferecidas no mercado monetário para as transações entre países. Para isso, os exportadores têm recorrido a bancos chineses e tomado empréstimo em RMB. No caso do exportador de soja, ele faria um empréstimo, converteria imediatamente RMB em real e liquidaria a operação com o banco chinês em seis meses, com o recebimento da venda para o comprador chinês.

No entanto, por que as empresas brasileiras não procuram soluções no mercado de derivativos financeiros de RMB para fazer hedge dos contratos, por exemplo, lançando mão de mecanismos como o non-deliverable forward (NDF), contratos de futuro, swap cambial e opções?

Menos conhecido e mais recente, esse mercado de derivativos em RMB ainda está em processo de amadurecimento. Os investidores estão sendo apresentados a esse tipo de operação. Tais derivativos são atualmente transacionados pela bolsa de valores da China e possuem poucas modalidades de operação. Os requisitos para um agente operar nesse sistema ainda são limitados e pouco divulgados no mercado. A liquidez dos contratos de derivativos é com frequência superior a um ano, período que não se ajusta tão bem a contratos comerciais físicos de liquidez de curto prazo.

Retomando nosso exemplo de exportador de soja com contrato de venda em RMB, ele teria no mercado de derivativos de RMB poucas opções de instrumento às quais recorrer. Além disso, ele precisaria recorrer a liquidações de derivativos geralmente acima de um ano, mesmo se seu negócio fosse de curtíssimo prazo.

\section{CONCLUSÃO}

Empresários e investidores brasileiros são reticentes em relação às características do RMB, uma moeda que vem se internacionalizando, mas que ainda enfrenta questões de liquidez, confiabilidade e previsibilidade. Ao mesmo tempo, esses agentes estão muito interessados em entender e explorar melhor as oportunidades de expandir seus negócios na Ásia usando contrato comercial em RMB para transações, por enquanto, de curto prazo, com seus parceiros chineses.

Os contratos em RMB podem ajudar a expandir a venda dos produtos brasileiros não só na China, mas também nos outros países asiáticos, que usam crescentemente a moeda chinesa. Além disso, embora o RMB não tenha um mercado de derivativos igual ao do dólar ou euro, a possibilidade de hedge de RMB no mercado monetário com os bancos chineses já ajuda a reduzir o risco cambial das empresas brasileiras nessas transações.

AMANDA LEITNER THOMAZONI > Mestre em Administração pela FGV EAESP e consultora na Suzano Papel e Celulose S.A. > amanda.Ithomazoni@gmail.com HSIA HUA SHENG > Professor de Finanças da FGV EAESP e vice-presidente do Bank of China (Brasil) S.A. > hsia.sheng@fgv.br
} 